\title{
A comparison of radiation doses to selected vital organs in the maxillo- facial region using three different settings on the Galileos CBCT machine housed in the Wits Dental Hospital.
}

\author{
SADJ September 2017, Vol 72 no 8 p350 - p354
}

DL Dimtchev', B Buch²

\begin{abstract}
A comparison of radiation doses to selected vital organs in the maxillo-facial region at three different settings on the Galileos ${ }^{\circledR}$ cone-beam computed tomography (CBCT) machine in the Wits Dental Hospital was conducted with the courtesy of the Department of Medical Physics of the Charlotte Maxeke Johannesburg Academic Hospital. The study made use of the RANDO ${ }^{\circledR}$ phantom and TLD- 100 detector chips which provided detailed mapping of the dose distribution from the Galileos CBCT machine. Sixtytwo Sanford ${ }^{\circledR}$ lithium fluoride dosimeters- (TLD- 100) were irradiated using a calibrated known x-ray source after having undergone a recommended annealing cycle.
\end{abstract}

The data showed acceptable consistency in the results. Association between the different imaging modalities was further investigated using Kruskal-Wallis equality-ofpopulations rank test and Chi-squared test. A $p$-value of $<0.05$ was considered statistically significant.

Since there do not appear to be major differences between the radiation doses for the different settings of the Galileos CBCT machine, the authors recommend the use of the combined setting at all times for optimum image quality.

\section{INTRODUCTION}

The currently most common usages of the cone beam machine have been for implant planning, diagnosis of ectopically placed teeth for orthodontics and to a lesser

1. Dimi L Dimtchev: Stomatology (Medical Academy Sofia); BDS Wits); MSc Dent (Wits). Division of Maxillo-Facial and Ora Radiology, Department of General Dental Practice, School of Ora Health Sciences, University of the Witwatersrand, Johannesburg.

2. Brian Buch: BSC Hons (Natal); SED (UCT); BDS (Wits); MSc Dent (Wits). Emeritus Professor-University of Pretoria, Visiting Professor and Part-time Consultant: Division of Maxillo-Facial and Ora Radiology, Department of General Dental Practice, School of Ora Health Sciences, University of the Witwatersrand, Johannesburg.

\section{Corresponding author}

Brian Buch:

Tel: 011488 4897, E-mail: Brian.Buch@wits.ac.za

\section{ACRONYMS}

ALARA: as low as reasonably achievable

CBCT: cone-beam computed tomography

Gy: Gray unit: the absorption of one joule of radiation energy per kilogram of matter

PMMA: polymethyl-methacrylate

TLDs: thermoluminescent dosimeters

$\mu S v$ : $\quad$ Sievert Unit of ionizing radiation

A measure of the health effect of radiation

extent for the diagnosis of pathoses in the maxillofacial region. ${ }^{1-3}$ This recent practice of using cone beam as a single primary technique, however, harbours risks of overexposing patients to excessive radiation together with possible misdiagnoses. The reason for the latter is the fact that the new dimension provided by a cone beam image requires advanced expertise in diagnosis, often beyond the scope of a general dentist. It must therefore be emphasized that a cone- beam image must not constitute a routine radiographic view but should require a definite indication for its use. Cone-Beam Computerised Tomography (hereafter referred to as CBCT) may ultimately contribute to improvement of patient care, but users must be aware of their adherence to the ALARA principle to prevent latent untoward effects of radiation. Radiation risk is frequently spoken about but all too often not taken seriously. A study done by Buch and Fensham in 2003 using thermoluminescent dosimeters (TLDs) and a female RANDO phantom ${ }^{4}$ showed that a panoramic X-ray examination from a Siemens Orthophos $^{\circledR}$ machine imparted to the thyroid no more than ten days of additional background radiation and to the eyes a mere two and a half days. ${ }^{4}$ Buch, Fensham and Maritz in 2009 compared absorbed doses to the eyes, thyroid and uterus imparted by a Gendex ${ }^{\circledR}$ panoramic machine with those from a fullmouth intraoral $X$-ray examination using films and digital technology. ${ }^{5}$ They found that the dose to the eyes from a full-mouth intraoral examination using films was higher than that from the panoramic machine although the dose to the thyroid was half that of the panoramic examination. 
These doses were much reduced when using digital technology. Low doses to the uterus were similar in all cases and were unchanged when a lead apron was used.5,6

In all the above experiments a $\mathrm{RANDO}^{\circledR}$ phantom was used. The Alderson RANDO phantom has been in use for over 30 years. ${ }^{4}$ It consists of a human skeleton surrounded by tissue-equivalent material. Such material approximates the average radiation density of human tissues; in fact a study published in 2001 concluded that the tissue equivalence of a RANDO phantom does not differ by more than $15 \%$ from that of a cadaver. The phantom is transected horizontally into $2.5 \mathrm{~cm}$ thick slices. Each slice has holes containing plugs which can be replaced with TLD chips. ${ }^{4}$

Current studies provide comparative measurements of doses from different CBCT equipment, but do not take into account dose differences which may occur at different settings of the same machine. ${ }^{7}$ In 2006 Ludlow et al used TLDs and a RANDO phantom to determine radiation doses of three different CBCT machines. ${ }^{8}$ Their study has clearly shown that considerable differences exist between the various makes of CBCT machines. Furthermore in 2008 Palomo et al. modified CBCT equipment to allow for different $\mathrm{mA}$ and $\mathrm{kV}$ choices. ${ }^{9}$ For this experiment TLD chips, a RANDO phantom and a fresh cadaver were used. ${ }^{4,9}$ Although the radiation dose in this instance was comparatively low, it resulted in a low quality image. ${ }^{9}$

A systematic review has revealed that no comparative doses corresponding to the different settings on the Galileos $^{\circledR}$ CBCT appear to be available. ${ }^{10}$

Doses quoted by the manufacturer are average full-body doses which have no relevance to specific vital organs at the different settings. Most purchasers of CBCT machines in South Africa are dentists. Their limited imaging and technical knowledge is largely accountable for the confusion encountered in clinical literature. Technical device settings and their properties were not constant in the abovementioned studies. Apart from the lack of evidence-based data for CBCT radiation doses, there was an associated inconsistency of terminology. The use of CBCT will undoubtedly improve patient care in the long term, but practitioners must be aware of their responsibilities in holistically interpreting the data collected at each examination.

In 2005 Tsiklakis et al. published a study in which seventyfive TLD-100 dosimeters and a male RANDO phantom were used to compare radiation doses imparted by the New Tom $^{\circledR} 9000$ CBCT machine with those from a standard panoramic machine. The result was that CBCT appeared to have a three to seven times higher risk compared with a panoramic examination. ${ }^{11}$

In all the above experiments thermoluminescent (TLD) dosimeter chips were used to monitor radiation doses, and these chips continue today to constitute the primary mode of the monitoring of radiation exposure.12,13 The reliability of the method was studied by Buch and Keddy in 1987 and successfully shown to have high fidelity. ${ }^{14}$ The authors showed that TLD chips provide an acceptably accurate measurement of doses of absorbed radiation to certain areas of the body during dental $\mathrm{x}$-ray examinations. TLD dosimeters allow for the determination of a wide range of absorbed doses. This makes them useful in dose detection from $\mu$ Gy to several Gy. TLDs are easy to transport, can be mailed and can be used for many different applications. ${ }^{12}$ TLD 100 dosimeter chips made from lithium fluoride (LiF) material have a wide potential in radiation dosimetry. They are accurate for X-, gamma, beta, electron and neutron radiations, are reusable and are nearly tissue- equivalent.12,13

When impurities are added to LiF, the forbidden region i.e. the band gap*, can trap electrons. Those trapped electrons represent the energy acquired in the process of irradiation. When the chips are heated with a laser the electrons return to the valence band and light is emitted. The emitted light is measured in a photomultiplier tube and the reading interpreted by algorithms contained in computer software..$^{12,13}$

* In solid-state physics, a band gap, also called an energy gap or bandgap, is an energy range in a solid where no electron states can exist.

Radiation received is cumulative throughout life..$^{15}$ It is therefore essential to reduce the number of radiographs taken and to choose the most appropriate imaging modality. The International Commission on Radiological Protection (ICRP) provides tissue-weighting factors, which represent the relative contribution of that organ or tissue to the overall risk. ${ }^{16}$ Salivary glands, thyroid gland and eyes are the most susceptible to radiation in the head and neck region. Tissue-weighting factors were not taken into consideration by the authors as the purpose of this study was to accurately measure and compare doses using different settings of the Galileos CBCT machine.

The diagnostic quality of the Galileos CBCT machine improves with increased contrast. This in turn increases the radiation dose. ${ }^{17}$ Diagnostic quality also improves with an increase in the field of view. Different clinicians use different parameters to achieve the desired result. ${ }^{18}$ The use of mandibular, maxillary or a combined setting of Galileos CBCT by clinicians appears to be subjective rather than for any specific indication. An operator may well believe that the patient is exposed to less radiation if a modality is used that provides half of the complete view. This practice, however, may lead to a radiograph of inferior diagnostic quality.

Many studies refer to full-body dose, and a literature search did not find studies measuring doses for specific vital organs in the head and neck for Galileos CBCT settings, which the current study aims to determine. It is accepted that the risk of exposure to ionizing radiation should be balanced with the potential benefit to the patient. An important strategy of any dental radiologic service is to ensure that a revised or newly developed radiographic protocol should be implemented at all teaching institutions, in line with the latest national radiological policy.

The Radiology section of the Wits Dental Hospital admits 12000 patients annually for radiographic examinations. During the first seven months of its installation, 168 CBCT examinations were performed on the Galileos machine, which is accessible to all registrars in the various fields of dentistry but whose expertise in the use of this new equipment is limited. It would appear that the increased radiation dose to patients was seldom considered. The need for a study that would provide guidelines for more effective and responsible use of the CBCT machine at the Wits Dental Hospital was therefore obvious. 


\section{AIMS}

The aim of this study was to measure the effective doses of radiation imparted by the Galileos $\mathrm{CBCT}^{*}$ using in the first instance each of the maxillary and mandibular settings only, followed by the combined maxillary and mandibular setting. The effective doses in all three settings were then compared.

*Dentsply/Sirona

\section{MATERIALS AND METHOD}

A set of sixty-six (66) TLD 100 detector chips (dosimeters) were used in this study. All 66 TLD chips were annealed in a PTW-LTDO ${ }^{\circledR}$ oven. The prescribed annealing procedure recommended by the manufacturer was followed: The chips were placed in each of 66 wells contained within a metal slab and preheated to $400^{\circ} \mathrm{C}$. They were kept at this temperature for three hours and thereafter kept at $100^{\circ} \mathrm{C}$ for an hour before being left to cool to room temperature. TLDs were kept in the metal slab and covered with a metal lid between the annealing and irradiation processes. Vacuum tweezers were used to transfer the TLDs at the time of measurement and calibration.

Since lithium fluoride chips vary from one to another in their responses to the same dose of radiation, selection and calibration process was necessary.12 All 66 annealed dosimeters were placed on a polymethyl-methacrylate (PMMA) phantom and exposed to a known dose of radiation i.e. $1 G y$ in a Siemens ${ }^{\circledR}$ Linear accelerator. The TLDs were then read in a HARSHAW ${ }^{\circledR}$ QS 3500 TLD reader.* A specific calibration factor was programmed into the reader. A 15\% tolerance was considered acceptable for the measurement of absorbed doses. Fifty-seven (57) TLDs gave similar readings and were selected for the experiment. The position of the chips remained unchanged in the reading plate during the experiment and each chip was allocated a unique code- A1A, A2A etc. Each of those procedures as well as the subsequent reading of the chips was carried out in the Department of Medical Physics.

*ThermoFisher Scientific Inc. Waltham, USA 02451

The phantom head had initially been scanned in a CT scanner in order to determine the exact positions into which the TLD detector chips were to be placed. The chips were then positioned within the head of the phantom in sites corresponding to the eyes, the thyroid and the parotid

Table 1: Mandibular/Maxillary readings for the different settings of the Galileos CBCT ( $\mu \mathrm{Sv})$.

\begin{tabular}{|l|c|c|c|}
\hline & Man/Max $1^{\text {st }}$ & Man/Max $2^{\text {nd }}$ & Man/Max $3^{\text {rd }}$ \\
\hline Thyroid Anterior & 277.9 & 64.23 & 132.2 \\
\hline Thyroid Posterior & 313.3 & 105.01 & 255.6 \\
\hline Right Parotid Deep & 181.1 & 120.9 & 107.8 \\
\hline $\begin{array}{l}\text { Right Parotid } \\
\text { Superficial }\end{array}$ & 104.6 & 57.57 & 85.69 \\
\hline $\begin{array}{l}\text { Left Parotid Deep } \\
\text { Left Parotid }\end{array}$ & 77.91 & 83.53 & 89.42 \\
\hline $\begin{array}{l}\text { Superficial } \\
\text { Right Eye }\end{array}$ & 87.70 & 80.73 & 81.37 \\
\hline Left Eye & 54.05 & 38.45 & 21.83 \\
\hline & 44.27 & 39.05 & 42.05 \\
\hline
\end{tabular}

glands. The head was then transported to the Radiology section of the Wits Dental Hospital and positioned in the Galileos CBCT machine for subsequent exposure.

Eight chips were used for each of the nine exposures.

The chips were positioned as follows:

- Thyroid gland- anterior (superficial) and posterior (deep).

- Parotid gland- right parotid deep, right parotid superficial, left parotid deep and left parotid superficial.

- Eyes- right eye (at the position of the lens), left eye (at the position of the lens).

The Galileos CBCT was set to VO1 HC, 85 kV, 42 mAs, for all exposures.

The constant position of the phantom head in the CBCT for all exposures was ensured by means of laser markers. Three different settings of the Galileos CBCT were used i.e. mandibular exposure only, maxillary exposure only and combined maxillary and mandibular exposure. Each set of exposures was repeated three times giving a total of nine exposures.

At the completion of all exposures the TLD detector chips were read in the TLD reader housed in the Department of Medical Physics.

An additional three annealing cycles and sequential readings were performed in order to determine the background radiation, using all 57 TLD detector chips.

Data was entered in an MS Excel spread sheet and analyzed using Stata under the guidance of two statisticians. The analysis included descriptive analysis of the study population. Cross-tabulations were also used to investigate associations between readings of the TLD detector chips for the different modalities. Association between the different imaging modalities was further investigated using Kruskal-Wallis equality-of-populations rank test and the Chi-squared test.19 A p-value of $<0.05$ was considered statistically significant.

\section{RESULTS}

Tables 1, 2 and 3 represent the raw data collected from all nine exposures. Background radiation, median values and statistical evaluation of the data are shown in Tables 4,5 and 6 .

\section{Table 2: Maxillary readings for the different settings of the} Galileos CBCT ( $\mu$ Sv).

\begin{tabular}{l|c|c|c|}
\hline & Man/Max $1^{\text {st }}$ & Man/Max $2^{\text {nd }}$ & Man/Max $3^{\text {rd }}$ \\
\hline Thyroid Anterior & 114.7 & 305.7 & 58.76 \\
\hline $\begin{array}{l}\text { Thyroid Posterior } \\
\text { Right Parotid Deep }\end{array}$ & 148.7 & 152.1 & 232.1 \\
\hline $\begin{array}{l}\text { Right Parotid } \\
\text { Superficial }\end{array}$ & 140.2 & 123.21 & 129.7 \\
\hline $\begin{array}{l}\text { Left Parotid Deep } \\
\text { Left Parotid }\end{array}$ & 89.91 & 154.8 & 72.59 \\
\hline $\begin{array}{l}\text { Superficial } \\
\text { Right Eye }\end{array}$ & 82.33 & 69.41 & 83.70 \\
\hline Left Eye & 39.91 & 36.85 & 41.51 \\
\hline
\end{tabular}


Table 3: Mandibular readings for the different settings of the Galileos CBCT ( $\mu$ Sv).

\begin{tabular}{l|c|c|c|} 
& Man/Max $1^{\text {st }}$ & Man/Max $2^{\text {nd }}$ & Man/Max $3^{\text {rd }}$ \\
\hline Thyroid Anterior & 133.5 & 347.7 & 90.88 \\
\hline $\begin{array}{l}\text { Thyroid Posterior } \\
\text { Right Parotid Deep }\end{array}$ & 151.9 & 471.0 & 100.9 \\
\hline $\begin{array}{l}\text { Right Parotid } \\
\text { Superficial }\end{array}$ & 32.71 & 192.3 & 53.35 \\
\hline $\begin{array}{l}\text { Left Parotid Deep } \\
\text { Left Parotid }\end{array}$ & 36.50 & 59.09 & 23.71 \\
\hline $\begin{array}{l}\text { Superficial } \\
\text { Right Eye }\end{array}$ & 28.19 & 27.71 & 25.45 \\
\hline \begin{tabular}{l} 
Left Eye \\
\hline
\end{tabular} & 15.54 & 15.59 & 19.12 \\
\hline
\end{tabular}

\section{DISCUSSION}

Despite the fixed position of the phantom for each set of exposures, small differences in dose readings for the various organs are apparent for the same machine settings. Certain of these differences may be related to scatter radiation, the annealing procedure or the stability of the TLD-100 detector chips. Scatter radiation is unpredictable and not necessarily related to the accuracy of the reading method. Nevertheless a minimum error of $10 \%$ in the accuracy of any single chip must be allowed for. ${ }^{13}$

Many of these small discrepancies may also be due to background radiation as much of the background radiation in the premises where the experiment took place emanates from the heavy surrounding concrete structures of the building.
Table 4 represents the mean values of three background exposures of the TLD chips in the reading plate. These readings fall mainly in the range between 3.811 and 15.61 $\mu \mathrm{S} v$ and are unlikely to significantly affect the result of the experiment.

Table 5 illustrates the median exposure values for the different settings of the Galileos CBCT machine. The readings for the thyroid (anterior) for all three settings does not differ more than $14.8 \%$ from the median value. For the thyroid (posterior) this value differs only by $26 \%$ between the mandibular and the combined maxillary/mandibular settings. A study done by Pauwels et al. also showed that the largest deviations in radiation doses were seen in the thyroid gland. ${ }^{18}$

The median values for maxillary and maxillary/ mandibular exposures are similar. These similarities are explained by the fact that CBCT scanning of the facial structures relies on a rotation centre for the scanning motion that approximates to the rami of the mandible for scanning of the posterior section of the jaws and to the centre of the floor of the mouth for scanning of the anterior section. These rotation centres absorb more radiation than do transiently exposed anatomical structures. Continuously exposed rotation centres are in very close proximity to the thyroid gland, resulting in the highest radiation doses as seen in this experiment. This conforms to a study by Ludlow et al. who thoroughly investigated these rotation centres. ${ }^{8}$ The calculated $p$-values for the three different settings for the thyroid are 0.82 (superficial) and 0.93 (deep). Statistically this is not considered significant.

\begin{tabular}{|c|c|c|c|c|c|c|c|c|}
\hline \multirow[t]{2}{*}{$\begin{array}{l}\text { TLD Position } \\
\text { letter } \downarrow\end{array}$} & \multicolumn{7}{|c|}{ Mean values out of three background exposures for positions $A$ to $G$} & \multirow[t]{2}{*}{$\begin{array}{l}\text { TLD positior } \\
\text { No: } \rightarrow\end{array}$} \\
\hline & A & B & C & D & $\mathrm{E}$ & $\mathrm{F}$ & G & \\
\hline 1 & 14.86 & 6.252 & 5.205 & 6.361 & 5.786 & 8.009 & 7.095 & 1 \\
\hline 2 & 11.39 & 8.553 & 5.209 & 7.292 & 9.194 & 9.636 & 10.02 & 2 \\
\hline 3 & 7.719 & 3.983 & 4.886 & 5.059 & 8.004 & 9.881 & 7.186 & 3 \\
\hline 4 & 5.394 & 15.61 & 3.818 & 5.883 & 6.553 & 6.418 & & 4 \\
\hline 5 & 4.353 & 6.789 & 6.103 & 9.369 & 6.129 & 4.474 & & 5 \\
\hline 6 & 20.41 & 6.686 & 7.734 & 9.509 & 5.754 & 6.325 & & 6 \\
\hline 7 & 6.171 & 8.683 & 5.416 & 6.249 & 9.648 & 5.219 & & 7 \\
\hline 8 & 5.526 & 5.785 & 3.811 & 6.666 & 5.434 & 5.268 & & 8 \\
\hline 9 & 9.351 & 5.583 & 4.652 & 5.510 & 4.066 & 5.126 & & 9 \\
\hline
\end{tabular}

Table 5: Median exposure values for the different settings of the Galileos CBCT ( $\mu$ Sv).

\begin{tabular}{l|ccc} 
& Mandibular/Maxillary Exposure & Maxillary Exposure & Mandibular Exposure \\
& $-85 \mathrm{kV} / 42 \mathrm{mAs} / \mathrm{HC}$ & $-85 \mathrm{kV} / 42 \mathrm{mAs} / \mathrm{HC}$ & $-85 \mathrm{kV} / 42 \mathrm{mAs} / \mathrm{HC}$ \\
\hline Thyroid Anterior & 131.00 & 152.9 & 133.5 \\
\hline Thyroid Posterior & 196.55 & 192.1 & 151.9 \\
\hline Right Parotid Deep & 114.35 & 124.205 & 53.35 \\
\hline Right Parotid Superficial & 88.44 & 114.395 & 32.44 \\
\hline Left Parotid Deep & 85.405 & 83.775 & 29.71 \\
\hline Left Parotid Superficial & 82.49 & 81.77 & 27.18 \\
\hline Right Eye & 33.68 & 40.71 & 15.54 \\
\hline Left Eye & 40.55 & 39.52 & 11.74
\end{tabular}


Table 6: Kruskal-Wallis equality of population rank test $\mathbf{O}=$ Observation $\mathbf{R}=$ Rank Sum

\begin{tabular}{|c|c|c|c|c|c|c|c|c|c|c|c|c|c|c|c|c|}
\hline \multirow[b]{2}{*}{ Type } & \multicolumn{2}{|c|}{$\begin{array}{l}\text { Thyroid } \\
\text { anterior }\end{array}$} & \multicolumn{2}{|c|}{$\begin{array}{l}\text { Thyroid } \\
\text { posterior }\end{array}$} & \multicolumn{2}{|c|}{$\begin{array}{c}\text { Right } \\
\text { Parotid } \\
\text { deep }\end{array}$} & \multicolumn{2}{|c|}{$\begin{array}{c}\text { Right } \\
\text { Parotid } \\
\text { superficial }\end{array}$} & \multicolumn{2}{|c|}{$\begin{array}{c}\text { Left } \\
\text { Parotid } \\
\text { deep }\end{array}$} & \multicolumn{2}{|c|}{$\begin{array}{c}\text { Left } \\
\text { Parotid } \\
\text { superficial }\end{array}$} & \multicolumn{2}{|c|}{$\begin{array}{l}\text { Right } \\
\text { Eye }\end{array}$} & \multicolumn{2}{|c|}{$\begin{array}{l}\text { Left } \\
\text { Eye }\end{array}$} \\
\hline & 0 & $\mathrm{R}$ & 0 & $\mathbf{R}$ & 0 & $\mathrm{R}$ & 0 & $\mathrm{R}$ & 0 & $R$ & 0 & $\mathbf{R}$ & 0 & $\mathrm{R}$ & 0 & $\mathrm{R}$ \\
\hline Mandibular & 3 & 21 & 3 & 17 & 3 & 14 & 3 & 7 & 3 & 6 & 3 & 6 & 3 & 6 & 3 & 6 \\
\hline Man/Max & 3 & 22 & 3 & 23 & 3 & 23 & 3 & 26 & 3 & 30 & 3 & 32 & 3 & 27 & 3 & 31 \\
\hline Maxillary & 3 & 23 & 3 & 26 & 3 & 29 & 3 & 33 & 3 & 30 & 3 & 28 & 3 & 33 & 3 & 29 \\
\hline Chi-squared & \multicolumn{2}{|c|}{0.386} & \multicolumn{2}{|c|}{0.144} & \multicolumn{2}{|c|}{1.076} & \multicolumn{2}{|c|}{5.589} & \multicolumn{2}{|c|}{6.000} & \multicolumn{2}{|c|}{6.182} & \multicolumn{2}{|c|}{6.409} & \multicolumn{2}{|c|}{6.045} \\
\hline P-value & \multicolumn{2}{|c|}{0.8243} & \multicolumn{2}{|c|}{0.9306} & \multicolumn{2}{|c|}{0.5840} & \multicolumn{2}{|c|}{0.0609} & \multicolumn{2}{|c|}{0.0498} & \multicolumn{2}{|c|}{0.0455} & \multicolumn{2}{|c|}{0.0406} & \multicolumn{2}{|c|}{0.0487} \\
\hline
\end{tabular}

Table 5 further illustrates that the values for the right parotid are higher than those for the left. This paradox has been mentioned in a number of studies and is due to fact that the rotation of the CBCT machine appears to have a bias, the right side being more heavily exposed than the left.17 As a result the calculated $p$-values for the three different settings for the deep parotid are 0.58 for the right and 0.05 for the left.

Statistically this too is not considered significant.

The same applies to the superficial parotid as illustrated in Table 5, the radiation values on the right side being higher than those on the left. There is a $25 \%$ difference between maxillary and combined maxillary/mandibular exposures on the right side and almost no difference on the left. Mandibular exposures on both sides are about 2.5 times less than both maxillary and combined exposures. However, the calculated $p$-value for the right side is 0.06 and that for the left is 0.0455 (0.05 if rounded).

These two $p$-values are considered statistically nonsignificant.

The lens of the eye, one of the most radiation-sensitive anatomical structures in the head region appears to be well protected owing to the engineering design of the Galileos CBCT machine. The radiation dose to the eye for the mandibular setting is equivalent to background radiation. For the maxillary and combined settings it is about two to two and a half times the background dose. It may appear surprising that the calculated $p$-value for the right eye is 0.0406 , which is statistically significant, whereas 0.0487 for the left eye (rounded to 0.05) is statistically non-significant. This very small difference could be due to the higher exposure on the right side and a greater amount of scatter radiation. ${ }^{17}$

Reproducibility of the results of this study is confirmed by the fact that there was no overall variation greater than $15 \%$ between repeated examinations. There were, however, significant deviations in the TLD readings for specific locations, especially in the region of the thyroid gland. Similar deviations were reported in 2006 by Ludlow et al. ${ }^{8}$ The surface orientation of the TLD chips was not taken into account as the TLDs were placed in the existing holes in the phantom, their position being constant for all exposures.

\section{CONCLUSION}

The results obtained justified the use of the combined setting for the attainment of improved diagnostic information. Since there were no major differences between the radiation doses for the different settings of the Galileos CBCT machine, the authors recommend the combined setting to be used at all times for optimal diagnostic quality.

\section{References}

1. Ahmad M, Jenny J, Downie M. Application of cone beam computed tomography in oral and maxillofacial surgery. Aust Dent J, 2012; 57(1):82-94.

2. Nervina JM. Cone beam computed tomography use in orthodontics. Aust Dent J, 2012; 57(1):95-102.

3. American Dental Association Council of Scientific Affairs. The use of cone-beam computed tomography in dentistry: an advisory statement from the American Dental Association Council on Scientific Affairs. J Am Dent Assoc, 2012 Aug;143(8):899-902.

4. The Rando® Phantom. Available at: http//www.phantomlab. com/products/rando.php Accessed September 11, 2013.

5. Buch B, Fensham R. Orthodontic radiographic proceduresHow safe are they? SADJ, 2003; 58(1) 6-10.

6. Buch B, Fensham R, Maritz MP. An assessment of the relative safety of dental x-ray equipment. SADJ, 2009; 64(8) 348-50.

7. Serhal C, Jacobs R, Gijbels F, Quirynen M, Van Steenberghe $D$, Bosmans $H$, Hermans R. Absorbed doses from spiral CT and conventional spiral tomography: a phantom vs. cadaver study. Clinical Oral Implants Research, 2001;12:473-8.

8. Ludlow JB, Brooks SL, Davies-Ludlow LE, Howerton B. Dosimetry of 3 CBCT units for oral and maxillofacial radiology. Dentomaxillofac Radiol, 2006; 35:219-26.

9. Palomo JM, Pejavar S, Hans MG, Gleveland. Influence of CBCT exposure conditions on radiation dose. Oral Surg Oral Med Oral Pathol Oral Radiology, 2008;105:773-82.

10. Kwong J, Palomo JM, Landers MA, Figueroa A, Hans MG. Image quality produced by different CBCT settings. Am J Orthod Dentifac Ortoped, 2008; 133(2):317-27.

11. Tsiklakis K, Donta C, Gavala S, Karayianni K, Kamenopoulou $\checkmark$, Hourdakis $C$. Dose reduction in maxillofacial imaging using low dose Cone Beam CT. European Journal of Radiology, 2005; 56: 413-7.

12. Kron T. Thermoluminiscence dosimetry and its applications in medicine-Part 2: History and applications. Australas Phys Eng Sci Med.1995; 18(1):1-25.

13. Kron T. Thermoluminiscence dosimetry and its applications in medicine-Part 1: Physics, materials and equipment. Australas Phys Eng Sci Med.1994; 17(4):175-94.

14. Buch B, Keddy RJ. Thermoluminescence dosimetry science. How reliable is it? JDASA. 1987;42(6): 311-7.

15. Puri S, Hu R, Quazi RR, Vocl S, Veazle P, Block R. Physicians' and midlevel providers' awareness of lifetime radiationattributable cancer risk associated with commonly performed CT studies: relationship to practice behavior. AJR Am J Roentgenol, 2012; 199: 1328-36.

16. Valentin J. The 2007 Recommendation of the International Commission on Radiological Protection. ICRP Publication 103. Ann ICRP, 2007; 37:1-322.

17. Fahrig R, DixonR, Payne T, Morin R, Gangulu A, Strobel N. Dose and image quality for a cone-beam C-arm CT system. Medical Physics, 2006; 33(12): 4541-50.

18. Pauwels R, Beinsberger J, Collaert B, Theodorakou C, Rogers J, Walker A, et al. Effective dose range for dental cone beam computed tomography scanners. European Journal of Radiology, 2010; 1-5.

19. Statistical Methods, Eight Edition, Snedecor and Cochrain, Iola State University Press, 1989; 142-4. 